\title{
EFFECT OF SHOCK REPOSITION ON OXYGEN SATURATION IMPROVEMENT IN VASOVAGAL SYNCOPE CASE
}

\author{
Ana Zakiyah, Emyk Windartik, Nur Muhammad \\ School of Health Sciences (STIKes) Bina Sehat PPNI, \\ Mojokerto, East Java
}

\begin{abstract}
BACKGROUND: Vasovagal syncope (a.k.a. neurocardiogenic syncope) occurs when a person faints because his/her body overreacts to a certain trigger, such as the sight of blood or extreme emotional distress. The vasovagal syncope causes heart rate and blood pressure to drop suddenly, which leads to reduced blood flow to the brain and causes brief loss of consciousness. Vasovagal syncope is usually harmless and requires no treatment. But the affected person may get injured during the episode. A shock reposition may help improve oxygen saturation in vasovagal syncope case. In this reposition the patient is laid on a flat, firm, plain and shaded place. The patient clothes are loosened in order to prevent choking neck. An aroma therapy may be given to the patient. This study aimed to determine the effectiveness of giving shock reposition on improving oxygen saturation in vasovagal syncope case.
\end{abstract}

SUBJECT AND METHODS: This was a quasi-experimental study, before and after with no control design. A sample of 26 students from SMAN 1 High School, Ngoro, Mojokerto, East Java, who experienced vasovagal syncope after taking part of a ceremony, was selected for this study. The independent variable was shock reposition. The dependent variable was oxygen saturation, which was measured using finger pulse oxymeter, before and after shock reposition.

RESULTS: Oxygen saturation (mean, SD) increased from (0.93; 0.01) before shock reposition to $(0.97$; 0.01) after shock reposition. There was a positive and statistically significant correlation of oxygen saturation before and after shock reposition $(\mathrm{r}=0.48 ; \mathrm{p}=0.014)$.

CONCLUSION: Providing shock reposition by laying down patient with vasovagal syncope on a flat, firm, and shaded place, can help improve oxygen saturation.

Keywords: vasovagal syncope, shock reposition, oxygen saturation 